\title{
Risk and its impacts on time and cost in construction projects
}

\author{
V. Aarthipriya ${ }^{a^{*}}$, G. Chitra ${ }^{\mathrm{b}}$ and J. Sevvel Poomozhic \\ ${ }^{a}$ ME Scholar, Infrastructure Engineering and Management, Department of Civil Engineering, Thiagarajar College of Engineering, Madurai, Tamil Nadu, \\ India \\ ${ }^{b}$ Professor, Department of Civil Engineering, Thiagarajar College of Engineering, Madurai, Tamil Nadu, India \\ ${ }^{c}$ Senior General Manager, Cost Audit, Bangalore, Karnataka, India \\ C H R O N I C L E \\ Article history: \\ Received: June 132020 \\ Received in revised format: June \\ 242020 \\ Accepted: June 262020 \\ Available online: \\ June 262020 \\ Keywords: \\ Risk Management \\ Schedule and Cost Impacts \\ Monte Carlo Simulation \\ Sensitivity Analysis

\section{A B S T R A C T} \\ The construction process is inherently prone to risks. Risk management is an essential and integral \\ part of project management on all construction projects. Risk analysis is one of the core components \\ of risk management that enables professionals to quantify and analyze risks that may pose potential \\ threats to project performance in terms of various parameters. This research was conducted to iden- \\ tify and analyze risks associated with residential construction in Bangalore. In this study, risk and \\ its impact on time and cost was identified and analyzed. Schedule impacts of project risks were \\ supplemented by conducting quantitative risk analysis such as Monte Carlo simulation and sensi- \\ tivity analysis using the Primavera risk analysis software. In case of cost, the cost variance was \\ found out and mitigation measures were given. Thus, by effectively managing the risks, organization \\ has more timely, comprehensive and deeper understanding of risks which in turn facilitates better \\ decision making and confidence to take on new ventures or even to accept higher level of risk.
}

\section{Introduction}

In the era of progressive globalization, it is hard to avoid risk, which has become an indispensable part of everyday life. Risk is present everywhere, in every aspect of our life (Mahendra et al., 2013; Mahamid \& Dmaidi, 2013). One of such aspects is the construction industry, where risk is an inherent element. Construction projects are always unique, and risks raises from a number of different sources (Lachapelle \& Hundozi, 2018). Risk is defined as any action or occurrence which will affect the achievement of project objectives. Risks and uncertainties inherent in the construction industries are more than any other industries (Chileshe \& Kikwasi, 2014). Many industries have become more proactive about using risk management techniques in project. Risk is an integral component of any project (Szymański, 2017). Risk is present in all projects irrespective of their size or sector. No project is totally free from risks. If risks are not properly analyzed and strategies are not trained to deal with them, the project is likely to lead to failures (Darshan et al., 2017; Choudhry et al., 2014). Thus, Effective risk management does not mean the removal of risk, which would seemingly be the cheapest option (Befrouei \& Taghipour, 2015).

There are various types of risks based on internal and external categories. The process of risk management was risk identification by historical data, theoretical analysis, expert options, etc., risk analysis by qualitative and quantitative methods, risk evaluation, risk treatment, and risk monitoring and control (ISO 31000-2018). Various literatures were conducted and reviewed. Eskander (2018) conducted a case * Corresponding author.

E-mail address: aarthipriya1997@gmail.com (V. Aarthipriya) 
study to rank the risk likelihood occurrence to use AHP method and its benefits in the Egyptian construction projects. Results present that financial risk is the first likelihood occurrence, Design risk was the 2nd rank with most likelihood occurrence after financial risk. 3rd rank is related to risk and construction risk at same time. The AHP is an essential approach that can be used to assess and analyze project risks during bidding and construction stages for construction project. Aderbag et al. (2018) have shown the cost and schedule risks associated to design and implementation of 20 housing units for low income people in Tripoli, Libya was analyzed. The cost and schedule risks are integrated and analyzed using Monte Carlo simulation. Two scenarios, pre and post mitigations, were conducted and compared with original plan. The results showed a risk reduction from $20 \%$ high, $25 \%$ medium and $55 \%$ low risk to $22 \%$ medium and $78 \%$ low with no high risks. Zeng et al. (2010) conducted risk management for OHS, environment and quality management under a case study in China using the Failure Modes and Effects Analysis was analyzed. It evaluated 20 potential risk factors and revealed that five potential risks, including "Holes in flooring on construction site", "Hit by falling objects", "Run over by operating equipment", "Elevator shaft falls", and "Scaffolding falls" are graded to be unacceptable. Moreover, it is more important to improvement for OHS, environment and quality in implementing an integrated risk management. Wang et al. (2004) carried out the risk management framework was developed in developing countries in which 28 critical risks were identified and categorized into three hierarchy levels (Country, Market and Project). It shows that the risks at Country level are more critical than that at Market level and the latter are more critical than that in Project level. A risk model, named Alien Eyes' Risk Model, was proposed which shows the three risk hierarchy levels and the influence relationship among risks.

The study was conducted in Residential development in the city of Bangalore, Karnataka. It consists of 16 towers or wings with $\mathrm{G}+18$ Floors and 2 basements. It spreads over 23.62 acres and offers over 1,284 apartments. It consists of 2, 3, and 4 BHK (Bedroom, Hall, and Kitchen) luxury apartments with $126.34 \mathrm{~m}^{2}, 144.93 \mathrm{~m}^{2}$ and $153.29 \mathrm{~m}^{2}, 213.68 \mathrm{~m}^{2}$ area. The Residential development consist of two phases - 1st phase and 2nd phase.

- First phase consists of wing 1 to 7 and wing 16 and

- Second phase includes wing 8 to 14 and wing 15 .

Wing 1 to 14 is full of 2 BHK and 3BHK apartments and Wing 15 and 16 consists full of 4 BHK apartments. The number of cark parking in the project is nearly 2295 (with wing 1 to 14 is about 1944 and wing 15 and 16 is about 223 respectively). The duration of project is nearly about 56 months. The entire area has full of both hard and soft rocks. The type of soil in the project area is Whitish/Brownish Clayey and Silty sand.

The aim of the work is to quantify and analyze risks that may pose potential threats to project performance in terms of time and cost and to manage the risks to these parameters. The objective of the work is to identify and measure the impact of risk on time, cost and to determine the risk assessment and to provide the risk mitigation measures.

\section{Methodology and Data Collection}

Various literatures were reviewed to identify the process of finding out the risks and various techniques were assessed to mitigate the risks. The data was collected from the Residential Development in the city of Bangalore, Karnataka. Various risks were identified in terms of time and cost.

The risk and its impact on time and cost was identified through interviews and by site visits. The analysis was carried out for various risk identified. In terms of time, the analysis such as Quantitative Risk Analysis - Monte Carlo Simulation and sensitivity analysis was carried out and analyzed using the Primavera risk analysis Software.

\subsection{Risk Impact on Time}

The actual and planned duration of each floors for each wing 4, 5, 6 and 7 were taken through site visits and interviews with the planning department and members of the organization. The planned and actual duration of each wing 4, 5, 6, and 7 is shown in Table 1, 2, 3, and 4 
Table 1

Planned and Actual Duration of Wing 4

\begin{tabular}{cccccc}
\hline Floors & \multicolumn{5}{c}{ WING 4 } \\
\cline { 2 - 6 } & $\begin{array}{c}\text { Start } \\
\text { Date }\end{array}$ & $\begin{array}{c}\text { End } \\
\text { Date }\end{array}$ & $\begin{array}{c}\text { Planned } \\
\text { duration } \\
\text { (days) }\end{array}$ & $\begin{array}{c}\text { Actual } \\
\text { duration } \\
\text { (days) }\end{array}$ & $\begin{array}{c}\text { Reasons } \\
\text { for delay }\end{array}$ \\
\hline Basement 1 & $10 / 09 / 19$ & $17 / 10 / 19$ & 60 & 38 & - \\
\hline Ground floor & $18 / 10 / 19$ & $30 / 11 / 19$ & 30 & 44 & Rainfall \\
First floor & $01 / 12 / 19$ & $30 / 12 / 19$ & $20-30$ & 29 & Material shortage \\
$\mathbf{2}^{\text {nd floor }}$ & $31 / 12 / 19$ & $12 / 01 / 20$ & 10 & 13 & Shortage of labors \\
$\mathbf{3}^{\text {rd floor }}$ & $6 / 01 / 20$ & $24 / 01 / 20$ & 10 & 10 & - \\
$\mathbf{4}^{\text {floor }}$ & $22 / 01 / 20$ & $31 / 01 / 20$ & 10 & 18 & $8 \mathrm{~mm}, 10 \mathrm{~mm}$ Steel shortage \\
\hline $\mathbf{5}^{\text {th }}$ floor & $30 / 01 / 20$ & $16 / 02 / 20$ & 10 & & 10 \\
\hline
\end{tabular}

Table 2

Planned and Actual Duration of Wing 5

\begin{tabular}{cccccc}
\hline Floors & \multicolumn{5}{c}{ WING 5 } \\
\cline { 2 - 6 } & $\begin{array}{c}\text { Start } \\
\text { Date }\end{array}$ & $\begin{array}{c}\text { End } \\
\text { Date }\end{array}$ & $\begin{array}{c}\text { Planned } \\
\text { duration } \\
\text { (days) }\end{array}$ & $\begin{array}{c}\text { Actual } \\
\text { duration } \\
\text { (days) }\end{array}$ & $\begin{array}{c}\text { Reasons } \\
\text { for delay }\end{array}$ \\
\hline Basement 1 & $28 / 8 / 19$ & $9 / 11 / 19$ & 60 & 72 & Rainfall \\
\hline $\begin{array}{c}\text { Ground floor } \\
\text { First floor }\end{array}$ & $10 / 11 / 19$ & $19 / 12 / 19$ & 30 & 29 & - \\
$\mathbf{2}^{\text {nd floor }}$ & $20 / 12 / 19$ & $09 / 01 / 20$ & $20-30$ & 20 & Delay in approving changes \\
$\mathbf{3}^{\text {rd }}$ floor & $10 / 01 / 20$ & $24 / 01 / 20$ & 10 & 16 & Barbender problem \\
$\mathbf{4}^{\text {th floor }}$ & $17 / 01 / 20$ & $05 / 02 / 20$ & 10 & 15 & Steel issue \\
\hline
\end{tabular}

Table 3

Planned and Actual Duration of Wing 6

\begin{tabular}{cccccc}
\hline Floors & \multicolumn{5}{c}{ WING 6 } \\
\cline { 2 - 5 } & $\begin{array}{c}\text { Start } \\
\text { Date }\end{array}$ & $\begin{array}{c}\text { End } \\
\text { Date }\end{array}$ & $\begin{array}{c}\text { Planned } \\
\text { duration } \\
\text { (days) }\end{array}$ & $\begin{array}{c}\text { Actual } \\
\text { duration } \\
\text { (days) }\end{array}$ & $\begin{array}{c}\text { Reasons } \\
\text { for delay }\end{array}$ \\
\hline Basement 2 & $06 / 03 / 19$ & $21 / 06 / 19$ & 90 & 106 & Excavation problem \\
\hline Basement 1 & $03 / 07 / 19$ & $24 / 11 / 19$ & 60 & 141 & Rainfall \\
Ground floor & $20 / 11 / 19$ & $18 / 12 / 19$ & 30 & 29 & - \\
\hline First floor & $19 / 12 / 19$ & $07 / 01 / 20$ & $20-30$ & 20 & Materials issue \\
2nd floor & $08 / 01 / 20$ & $23 / 01 / 20$ & 10 & 16 & No adequate labors \\
\hline 3rd floor & $18 / 01 / 20$ & $01 / 02 / 20$ & 10 & 15 & Steel issue \\
4th floor & $29 / 01 / 20$ & $12 / 02 / 20$ & 10 & 15 & Labor payment issue \\
\hline 5th floor & $07 / 02 / 20$ & $22 / 02 / 20$ & 10 & 16 & \\
\hline
\end{tabular}

\section{Table 4}

Planned and Actual Duration of Wing 7

\begin{tabular}{|c|c|c|c|c|c|}
\hline \multirow[b]{2}{*}{ Floors } & \multicolumn{5}{|c|}{ WING 7} \\
\hline & $\begin{array}{l}\text { Start } \\
\text { Date }\end{array}$ & $\begin{array}{l}\text { End } \\
\text { Date }\end{array}$ & $\begin{array}{c}\text { Planned } \\
\text { duration } \\
\text { (days) }\end{array}$ & $\begin{array}{c}\text { Actual } \\
\text { duration } \\
\text { (days) }\end{array}$ & $\begin{array}{l}\text { Reasons } \\
\text { for delay }\end{array}$ \\
\hline Basement 2 & $08 / 04 / 19$ & $29 / 07 / 19$ & 90 & 122 & Rock excavation issue \\
\hline Basement 1 & $25 / 7 / 19$ & $30 / 09 / 19$ & 60 & 68 & Rainfall \\
\hline Ground floor & $11 / 08 / 19$ & $31 / 10 / 19$ & 30 & 81 & Rainfall \\
\hline First floor & $31 / 10 / 19$ & $3 / 12 / 19$ & $20-30$ & 33 & - \\
\hline $2^{\text {nd }}$ floor & $4 / 12 / 19$ & $20 / 12 / 19$ & 10 & 17 & Lack of labour \\
\hline $3^{\text {rd }}$ floor & $12 / 12 / 19$ & $05 / 01 / 20$ & 10 & 23 & Materials issue \\
\hline $4^{\text {th }}$ floor & $27 / 12 / 19$ & $18 / 01 / 20$ & 10 & 21 & $\begin{array}{l}\text { Delay in performing } \\
\text { inspection }\end{array}$ \\
\hline $5^{\text {th }}$ floor & $11 / 1 / 20$ & $29 / 01 / 20$ & 10 & 18 & Lack of steel \\
\hline $6^{\text {th }}$ floor & $25 / 01 / 20$ & $11 / 02 / 20$ & 10 & 18 & $\begin{array}{l}\text { Steel \& Barbender } \\
\text { problem }\end{array}$ \\
\hline $7^{\text {th }}$ floor & $06 / 02 / 20$ & $21 / 02 / 20$ & 10 & 16 & $\begin{array}{c}\text { Reinforcement for } 7 \\
\text { days - steel }\end{array}$ \\
\hline 8th floor & $12 / 02 / 20$ & $03 / 03 / 20$ & 10 & 21 & Material issue \\
\hline $9^{\text {th }}$ floor & $21 / 02 / 20$ & $12 / 03 / 20$ & 10 & 21 & Delay in inspection \\
\hline $10^{\text {th }}$ floor & $07 / 03 / 20$ & $20 / 03 / 20$ & 10 & 13 & Delay due to labour \\
\hline
\end{tabular}


From various site visits and the data collected from various wings, the main reasons for delays is due to Rock Excavation, Shortage of labors, Shortage of materials, Delay in approving changes, Delay in performing inspection.

\subsection{Risk Impact on Cost}

To assess the cost related risk and its impact on the project are evaluated by collecting the data such as the cost structure of the entire project. The cost structure of the entire residential development was collected. In this cost structure, the total cost of the project for both Phase 1 and 2 was nearly Rs. 5,365,253,774.70. Currently the Phase 1 project consist of wing 4, 5, 6 and 7 was running. The Prorata amount estimated was about 166,101,437.55 and Actual amount spent was nearly Rs.196,836,149. The Prorata amount and the Actual amount spent for each activity was shown in Table 5. The quantity of excavated hard rock and cost incurred for excavation was shown in Table 6.

Table 5

Cost structure of each activity

\begin{tabular}{lccc} 
& Description & Prorata & Actual \\
\hline & Preliminary & $\mathbf{4 3 , 2 9 1 , 6 4 8 . 8 8}$ & $\mathbf{6 0 , 6 4 1 , 5 0 8 . 2 0}$ \\
Staff salary & & 5931936.6 & $8,944,979.99$ \\
Site operating expenses & $5,237,578.44$ & $6,806,577.29$ \\
Labor paid extra & & 2983254.16 & 5226186.74 \\
Security & & 449338.82 & $1,526,435.93$ \\
Mobilization & Structure & $16,238,704.21$ & $25,608,222.42$ \\
Earth work & & $\mathbf{6 1 , 3 8 2 , 7 5 8 . 0 6}$ & $\mathbf{7 4 , 5 6 0 , 7 5 2 . 7 8}$ \\
Concrete works & & $13,516,667.53$ & $21,413,422.89$ \\
Reinforcement & & $12,137,237.18$ & $12,894,828.01$ \\
Formwork & Marketing office \& Mockup & $19,590,593.57$ & $23,985,322.00$ \\
\multicolumn{2}{c}{ Not estimated as per site consumption } & $14,138,289.77$ & $16,267,179.87$ \\
\hline & Total & $\mathbf{6 1 , 4 2 7 , 0 3 0 . 6 1}$ & $\mathbf{6 1 , 4 2 7 , 0 3 0 . 6 1}$ \\
\hline
\end{tabular}

Table 6

Quantity of excavated hard rock and cost incurred

\begin{tabular}{cccc}
\hline Wing & Month & Quantity $\left.\mathbf{( m}^{\mathbf{3}}\right)$ & Cost (Rs.) \\
\hline \multirow{3}{*}{$1-7$} & January - October & 13734 & 31107510 \\
& November & 750 & 1698750 \\
& December & 2000 & 4530000 \\
16 & January & 2200 & 4983000 \\
\hline
\end{tabular}

Total cost of excavation of hard rock

Rs. 43981770

\section{Analysis of Risks}

From the data collected, the risk and its impact related to time was analyzed using the Primavera risk analysis software - version 8.7.5 and also, risk related to cost were assessed.

\subsection{Primavera Risk Analysis - Time}

Simulations are typically performed using the Monte Carlo technique, the project model is computed and iterated many times, with the input values (activity durations) chosen at random for each iteration from the probability distributions of these variables. For a schedule risk analysis, Oracle primavera risk analysis is used to modeling and perform Monte Carlo simulation. The schedule risk analysis was conducted for wing 7 from the floor 10. To develop schedule risk model, primavera risk analysis tool was 
used throughout importing the original schedule from Primavera P6 R8.3 which is shown in Figure 1. The schedule risk analysis starts with applying uncertainty to the schedule activities duration and Triangular distribution is used with the max, min and most likely values.

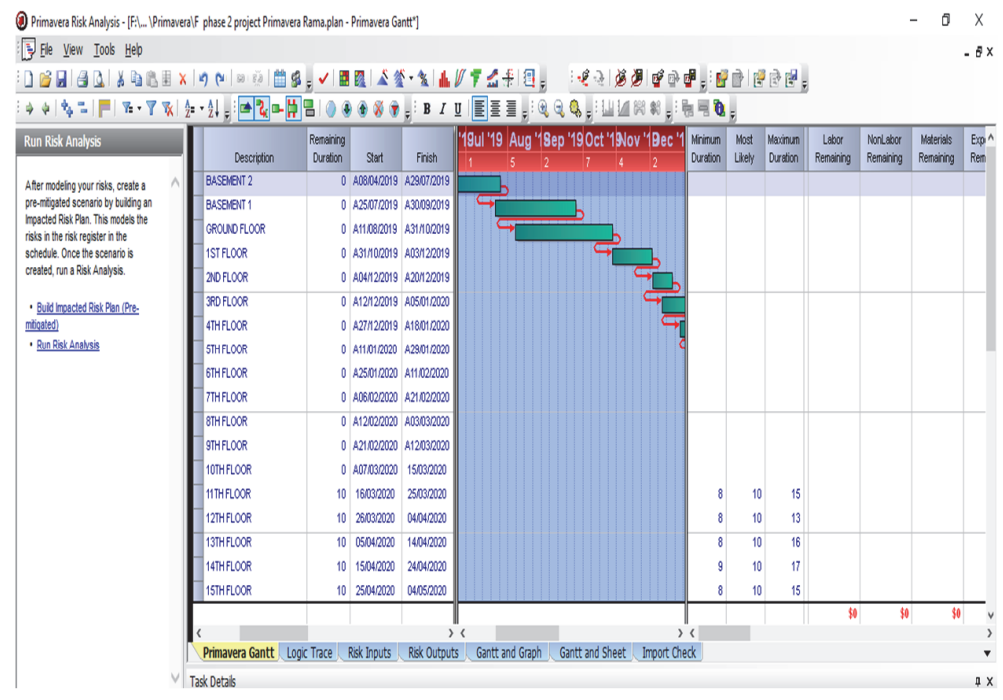

Fig. 1. Schedule Risk Model

After applying uncertainty to the schedule activities, risk register is built up to identify risk events and linked it to activities in order to complete Monte Carlo analysis and finally build the impacted risk plan. Risks in the Risk Register has been created based on the reasons of delay of data collected from wing 4, 5,6 and 7 of various site visits. The risk register created in the primavera risk analysis was shown in Fig. 2. The risks such as Pandemic disaster, shortage of labors, shortage of materials, delay in performing inspection, late performance by subcontractors and delay in approving changes in the scope of work. After creating the risk register, the risks were assigned to each floors of wing 7 . The final step and before of create analysis graphs are running the analysis (running Monte Carlo simulation), the analysis run cover 1000 iterations. The separate analysis was carried for pre-mitigation, post-mitigation, and original plan.

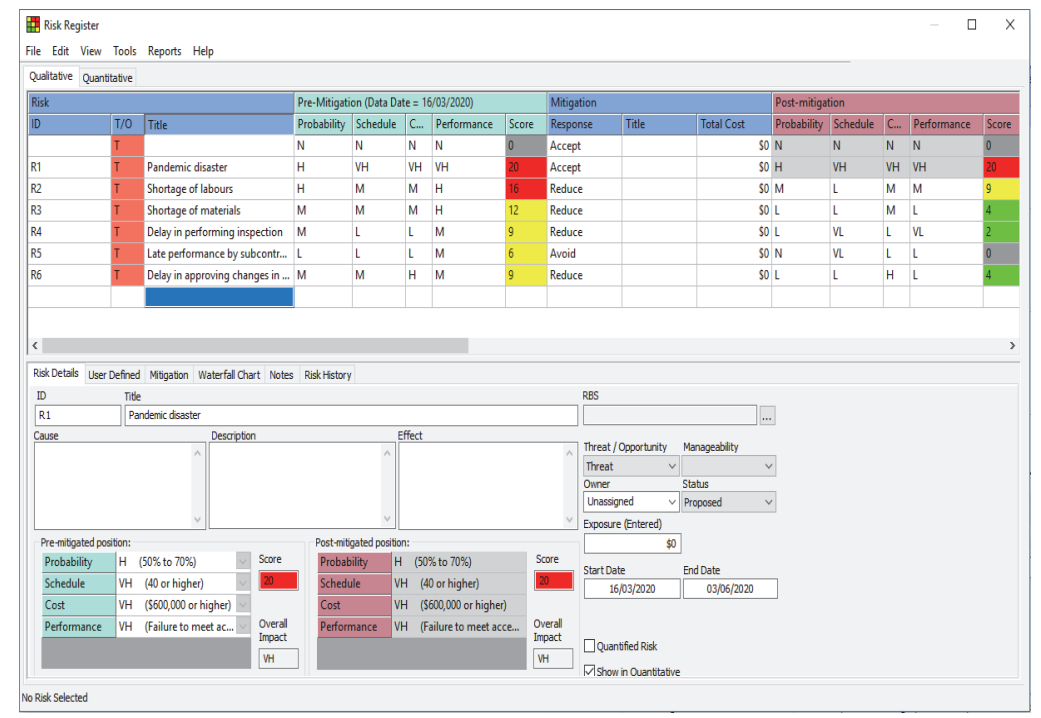

Fig. 2. Risk Register for Schedule Risk Model

\subsection{Cost Analysis of The Project}

The cost structure of the project was collected from costing department. The estimated cost of the project is about Rs. 536 crores. The cost estimated of the project till the month of August was about Rs.166,101,437.55 and the actual cost incurred is about Rs. 196,836,149. Therefore, the cost variance is 
about Rs. 30,734,711.45. The reasons for cost overrun was due to Material Rate fluctuation, Improper planning of resources, Improper quantity estimation, Improper investigation on soil conditions and shown in Table 7. Excavation of hard rock costs nearly Rs. 43981770 till February 2020. The excavation of hard rock per $\mathrm{m}^{2}$ cost is Rs. 2235 using core cutting machine.

Table 7

Reasons for Cost Overrun

\begin{tabular}{|c|c|c|c|c|}
\hline Description & Prorata (Rs.) & Actual (Rs.) & $\begin{array}{l}\text { Difference } \\
\text { (Rs.) }\end{array}$ & Reasons \\
\hline Preliminary & 43291648.88 & 60641508.20 & $17,349,859.3$ & - \\
\hline Staff salary & 5931936.6 & $8,944,979.99$ & $3,013,043.39$ & $\begin{array}{l}\text { More deployment than } \\
\text { Budgeted }\end{array}$ \\
\hline $\begin{array}{l}\text { Site operating } \\
\text { expenses }\end{array}$ & $5,237,578.44$ & $6,806,577.29$ & $1,568,998.85$ & $\begin{array}{l}\text { Printer rent \& Cab } \\
\text { Hiring charges are not budgeted, water } \\
\text { consumption is more than budgeted }\end{array}$ \\
\hline $\begin{array}{l}\text { Labor paid } \\
\text { extra }\end{array}$ & 2983254.16 & 5226186.74 & 2242932.58 & Marking, shifting and Curing labors \\
\hline Security & 449338.82 & $1,526,435.93$ & $1,077,097.11$ & $\begin{array}{l}\text { Excess deployment of security guards \& } \\
\text { supervisor }\end{array}$ \\
\hline Mobilization & 16238704.21 & 25608222.42 & $9,369,518.21$ & $\begin{array}{l}\text { Difference in actual rate of bore wells, } \\
\text { debris removal and barrication }\end{array}$ \\
\hline Structure & 61382758.06 & 74560752.78 & 13177994.72 & - \\
\hline Earth work & $13516,667.53$ & 21413422.89 & $7,896,755.36$ & $\begin{array}{l}\text { Excess charge of Hard rock, soft rock and soil exc } \\
\text { avation }\end{array}$ \\
\hline Concrete works & 12137237.18 & 12894828.01 & $757,590.83$ & \\
\hline Reinforcement & 19590593.57 & 23985322.00 & $4,394,728.43$ & $\begin{array}{l}\text { RMC \& Steel Rate } \\
\text { Fluctuation }\end{array}$ \\
\hline Formwork & 14138289.77 & 16267179.87 & $2,128,890.10$ & \\
\hline $\begin{array}{l}\text { Marketing } \\
\text { Office }\end{array}$ & 61427030.61 & 61427030.61 & - & - \\
\hline $\begin{array}{l}\text { Not estimated } \\
\text { as per site } \\
\text { consumption }\end{array}$ & - & $206,857.41$ & $206,857.41$ & $\begin{array}{l}\text { Additional supporting } \\
\text { rods given to footings }\end{array}$ \\
\hline Total & $166,101,437.5$ & $196,836,149$ & 30,734,711 & - \\
\hline
\end{tabular}

\section{Results and Discussions}

The study deals with the results of risk analysis with respect to impact on Time, and Cost. Thus, the original, pre-mitigation and post-mitigation duration using Monte Carlo Simulation and Tornado graph for schedule sensitivity was found out in case of time and mitigation measures for cost overrun was given.

\subsection{Primavera Risk Analysis - Time}

After the analysis using 1000 iterations in Primavera risk analysis, sensitivity analysis was done using the tornado graph. Sensitivity analysis helps to determine which risks have the most potential impact on the project using tornado diagram, as shown in Fig. 3 in which the R1 (Pandemic disaster) has most potential impact on overall project schedule. 


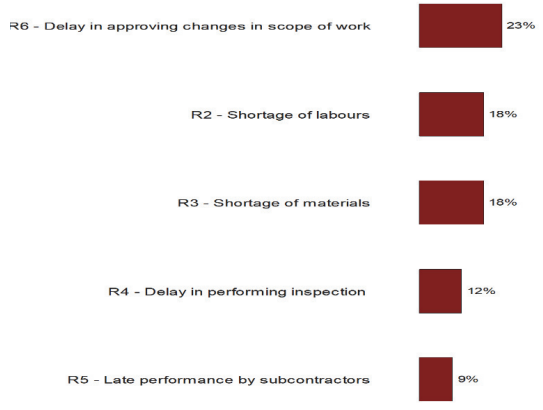

Fig. 3. Schedule Sensitivity Tornado Graph

The Monte Carlo simulation for original plan can be obtained by normal analysis. But in case of preand post- mitigation plan, it can be obtained by assigning risk in impacted risk plan. The Monte Carlo simulation was carried out by using 1000 iterations for original plan, Pre-mitigation, and Post mitigation plan.

\section{a. Original Planned Duration}

Fig. 4 represents the completion of the whole works cumulative distribution histogram for original plan. At $50 \%$ probability the project completion of whole works could be finished at 11/06/2020 (88 days), At $80 \%$ probability the project completion of whole works could be finished at 14/06/2020 (91 days).

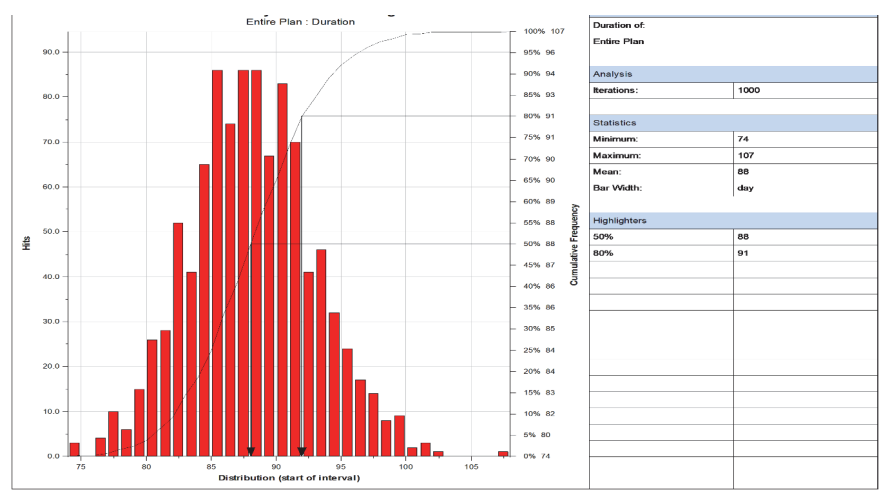

Fig. 4. Original Plan Finish Duration Histogram

\section{b. Pre-mitigation Duration}

Fig. 5 represents the completion of the whole works cumulative distribution histogram for pre-mitigation plan. At $50 \%$ probability the project completion of whole works could be finished at 17/08/2020 (155 days), At $80 \%$ probability the project completion of whole works could be finished at 12/09/2020 (181 days).

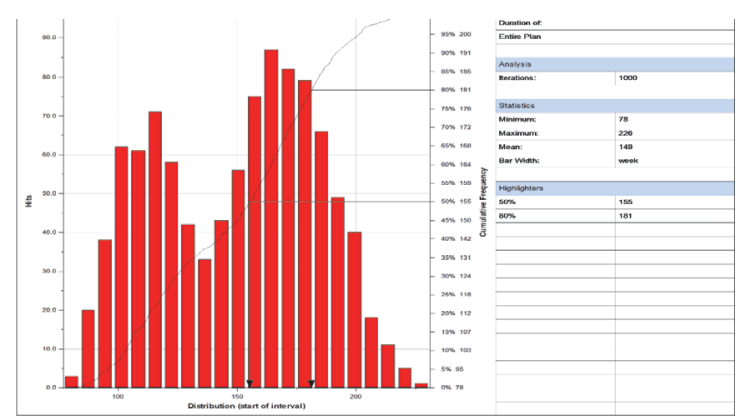

Fig. 5. Pre-mitigation Finish Duration Histogram

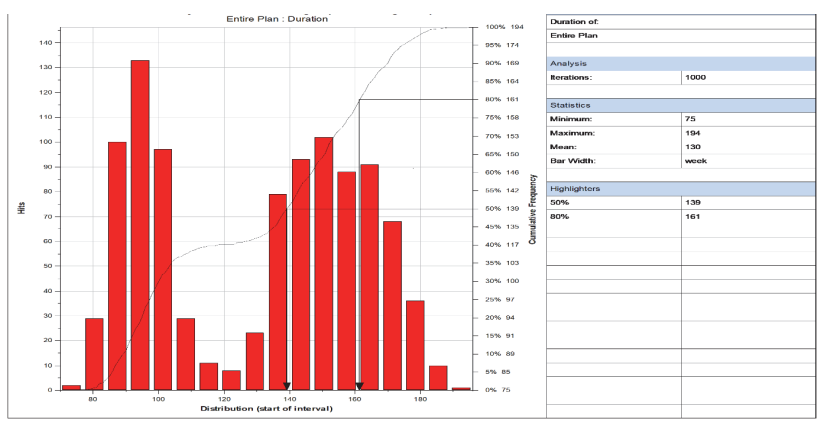

Fig. 6. Post-mitigation Finish Duration Histogram 


\section{c. Post-mitigation Duration}

Fig. 6 represents the completion of the whole works cumulative distribution histogram for post-mitigation plan. At 50\% probability the project completion of whole works could be finished at 01/08/2020 (155 days), At $80 \%$ probability the project completion of whole works could be finished at 23/08/2020 (181 days). Finally risk matrix was created for pre and post mitigation plan which shows the $5 \times 5$ matrix with probability in $\mathrm{y}-$ axis and impacts in $\mathrm{x}$-axis. The probability and impact were separated in Very low, Low, Medium, High, Very High category. The red zone shows the high risks, yellow zones shows the medium risks, and green zones shows the low risks which was shown in Fig. 7 and Fig. 8 shows the comparison of duration probability graph of original, pre-, and post- mitigation plan.

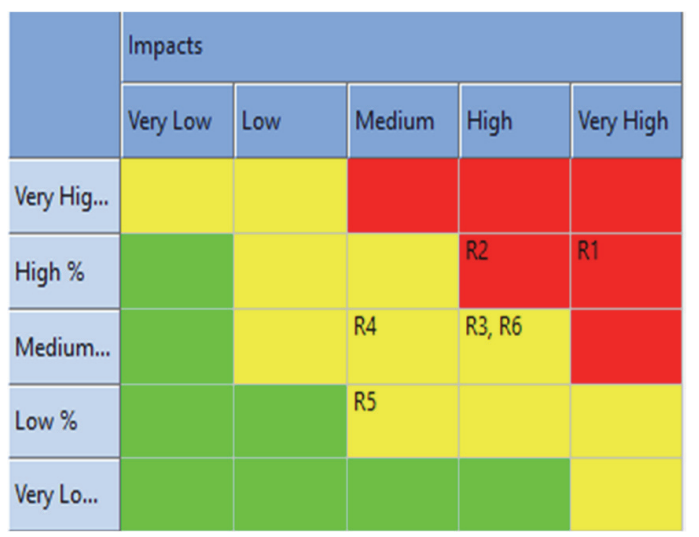

(a)

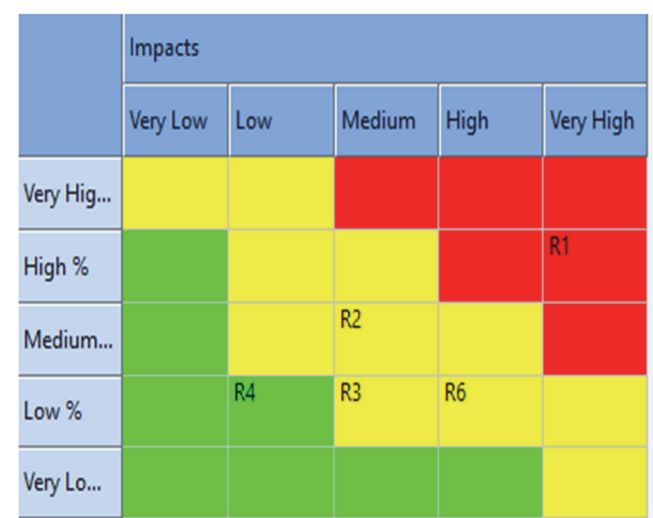

(b)

Fig. 7. Risk Matrix (a)Pre-mitigation (b)Post-mitigation

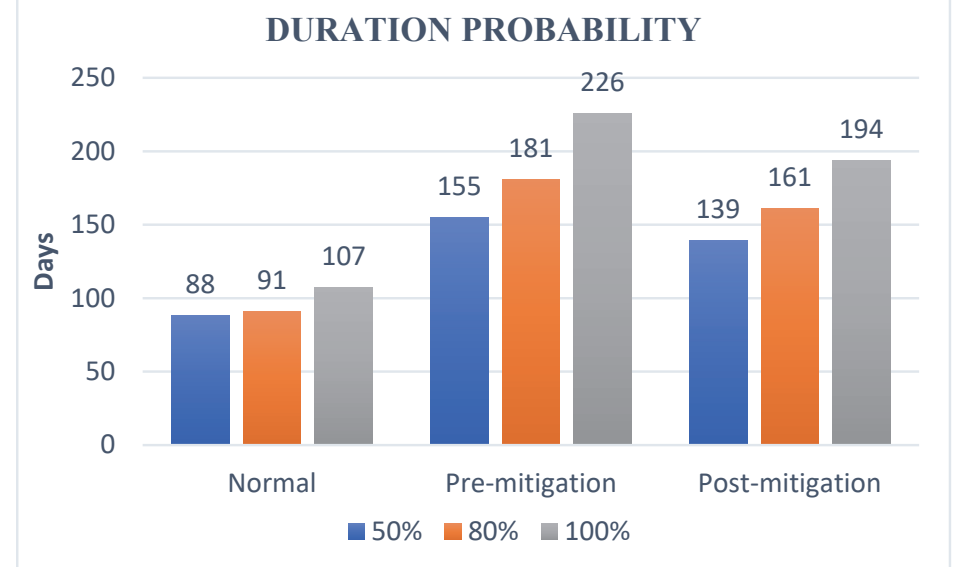

Fig. 8. Comparison of Normal, Pre-Mitigation and Post-Mitigation Duration Graph

From Fig. 7a and b, during pre- mitigation, the risk matrix shows that the R1 (Pandemic disaster) and R2 (shortage of labors) are high risk; R3, R4, R5 and R6 (Shortage of materials, delay in performing inspection, late performance by subcontractors, delay in approving changes in the scope of work) are medium risks. After the post-mitigation, the risk matrix shows that the R1 is same as high risk because this risk should be accepted; R2, R3, and R6 are reduced to medium risk; R4 is low risk and R5 risks should be avoided and hence it is neglected.

From Fig. 8, the duration probability graph shows that by the probability of $80 \%$, the original duration is 91 days, by incorporating risks, the pre-mitigation duration increases tremendously to 181 days. After applying post-mitigation plan, the duration is decreased to 161 days. This is same in case of both $50 \%$ and $100 \%$ probability.

\subsection{Risk Impact on Cost}


The estimated cost of the project is about Rs. 536 crores. The cost estimated of the project till the month of August was about Rs.166,101,437.55 and the actual cost incurred is about Rs. 196,836,149. Therefore, the cost variance is about Rs. 30,734,711.45. The reasons for cost overrun was due to Material Rate fluctuation, Improper planning of resources, Improper quantity estimation, Improper investigation on soil conditions. Excavation of hard rock costs nearly Rs. 43981770 till February 2020. The excavation of hard rock per $\mathrm{m}^{2}$ cost is Rs. 2235 using core cutting machine. Measures of cost overrun was thorough planning before the project begins, hire experienced and reputable quantity estimators and designers by identifying potential problems by conducting field measurements and discovering possible hidden conditions prior to starting work, identifying of new vendors offering less quoting price for excavation for upcoming wings and also can change the underground parking design of the project.

\section{Conclusion}

Risk management is the identification, evaluation and prioritization of risks followed by economical application of resources to minimize, monitor, and control the probability or impact of unfortunate events. In this study, the risk and its impact of time, and cost was identified and analyzed. In case of impact on time, the quantitative risk analysis is carried out in primavera risk analysis software in which the schedule sensitivity using tornado graphs and Monte Carlo simulations are carried out. The results show that the by the probability of $80 \%$, the original duration is 91 days, by incorporating risks, the premitigation duration increases tremendously to 181 days. After applying post-mitigation plan, the duration is decreased to 161 days. This is same in case of both $50 \%$ and $100 \%$ probability and risk matrix for pre-mitigation for post-mitigation was also created. In case of impact on cost, the cost variance is about Rs. 30,734,711.45. The reasons for cost overrun was due to Material Rate fluctuation, Improper planning of resources, Improper quantity estimation, Improper investigation on soil conditions. Hence various mitigation measures were given for reduce the cost overrun. Thus, this helps the engineers and organization to sort out the risks and avoid time and cost overrun.

\section{References}

Aderbag, A.M., Saber Kh. Elmabrouk., \& Sherif, A.M. (2018). Risk analysis related to costing and scheduling of construction projects. Proceedings of the International Conference on Industrial Engineering and Operations Management Bandung, Indonesia.

Befrouei, M. A. R., \& Taghipour, M. (2015). Identification and management of risks in construction projects. American Journal of Civil Engineering, 3(5), 170-177.

Chileshe, N., \& Kikwasi, G. J. (2014). Risk assessment and management practices (RAMP) within the Tanzania construction industry: Implementation barriers and advocated solutions. International Journal of Construction Management, 14(4), 239-254.

Choudhry, R. M., Aslam, M. A., Hinze, J. W., \& Arain, F. M. (2014). Cost and schedule risk analysis of bridge construction in Pakistan: Establishing risk guidelines. Journal of Construction Engineering and Management, 140(7), 04014020.

Darshan, E., Arun Kumar, C.J., Rajeeva S.J., \& Narayana G. (2017). Analysis of risk management in residential building using Primavera Web Software. International Journal of Advance Research and Innovative Ideas in Education, 3(4).

Lachapelle, E., \& Hundozi, B. (2018). ISO 31000:2018, Risk management-guidelines, www.pecb.com

Eskander, R. F. A. (2018). Risk assessment influencing factors for Arabian construction projects using analytic hierarchy process. Alexandria Engineering Journal, 57(4), 4207-4218.

IS/ISO 31000 (2009): Risk Management - Principles and Guidelines [MSD 4: Management and Productivity]

Mahamid, I., \& Dmaidi, N. (2013). Risks leading to cost overrun in building construction from consultants' perspective. Organization, Technology \& Management in Construction: An International Journal, 5(2), 860-873.

Mahendra, P. A., Pitroda, J. R., \& Bhavsar, J. J. (2013). A study of risk management techniques for construction projects in developing countries. International Journal of Innovative Technology and Exploring Engineering, 3(5), 139-142. 
Szymański, P. (2017). Risk management in construction projects. Procedia Engineering, 208, 174182.

Wang, S. Q., Dulaimi, M. F., \& Aguria, M. Y. (2004). Risk management framework for construction projects in developing countries. Construction Management and Economics, 22(3), 237-252.

Zeng, S. X., Tam, C. M., \& Tam, V. W. (2010). Integrating safety, environmental and quality risks for project management using a FMEA method. Engineering Economics, 66(1).

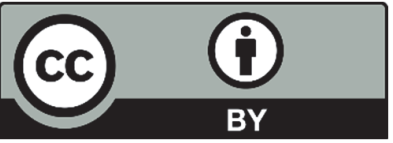

(C) 2020 by the authors; licensee Growing Science, Canada. This is an open access article distributed under the terms and conditions of the Creative Commons Attribution (CCBY) license (http://creativecommons.org/licenses/by/4.0/). 